\title{
Quantifying air quality benefits resulting from few autonomous vehicles stabilizing traffic
}

\author{
Raphael E. Stern, $\quad$ Yuche Chen ${ }^{\dagger} \quad$ Miles Churchill, \\ Maria Laura Delle Monache, Benedetto Piccoli ॥ Benjamin Seibold ** \\ Jonathan Sprinkle,$^{\dagger \dagger} \quad$ Daniel B. Work ${ }^{\ddagger \dagger}$
}

\begin{abstract}
It is anticipated that in the near future, the penetration rate of vehicles with some autonomous capabilities (e.g., adaptive cruise control, lane following, full automation, etc.) will increase on roadways. This work investigates the potential reduction of vehicular emissions caused by the whole traffic stream, when a small number of autonomous vehicles (e.g., $5 \%$ of the vehicle fleet) are designed to stabilize the traffic flow and dampen stop-and-go waves. To demonstrate this, vehicle velocity and acceleration data are collected from a series of field experiments that use a single autonomous-capable vehicle to dampen traffic waves on a circular ring road with 20 to 21 human-piloted vehicles. From the experimental data, vehicle emissions (hydrocarbons, carbon monoxide, carbon dioxide, and nitrogen oxides) are estimated using the MOVES emissions model. This work finds that vehicle emissions of the entire fleet may be reduced by between $15 \%$ (for carbon dioxide) and $73 \%$ (for nitrogen oxides) when stop-andgo waves are reduced or eliminated by the dampening action of the autonomous vehicle in the flow of human drivers. This is possible if a small fraction $(\sim 5 \%)$ of vehicles are autonomous and designed to actively dampen traffic waves. However, these reductions in emissions apply
\end{abstract}

*email: raphael.stern@vanderbilt.edu, Department of Civil and Environmental Engineering, University of Illinois at Urbana-Champaign, 205 N. Mathews Ave, Urbana, IL 61801, USA and Department of Civil and Environmental Engineering, Vanderbilt University, 2301 Vanderbilt Place, Nashville, TN 37235-1826, USA.

${ }^{\dagger}$ Department of Civil and Environmental Engineering, Vanderbilt University, 2301 Vanderbilt Place, Nashville, TN 37235-1826, USA.

${ }_{\ddagger}^{\ddagger}$ Department of Civil and Environmental Engineering, University of Illinois at Urbana-Champaign, 205 N. Mathews Ave, Urbana, IL 61801, USA

$\S$ Department of Civil and Environmental Engineering, University of Illinois at Urbana-Champaign, 205 N. Mathews Ave, Urbana, IL 61801, USA

IInria, University Grenoble Alpes, CNRS, GIPSA-lab, F-38000 Grenoble, France.

"Department of Mathematical Sciences, Rutgers University - Camden, 311 N. 5th St, Camden, NJ 08102, USA.

** Department of Mathematics, Temple University, 1805 North Broad Street, Philadelphia, PA 19122, USA.

${ }^{\dagger \dagger}$ Department of Electrical and Computer Engineering, University of Arizona, 1230 E. Speedway Blvd, Tucson, AZ 85721-0104, USA.

¥† Department of Civil and Environmental Engineering, Vanderbilt University, 2301 Vanderbilt Place, Nashville, TN 37235-1826, USA. 
to driving conditions under which stop-and-go waves are present. Less significant reductions in emissions may be realized from a deployment of AVs in a broader range of traffic conditions.

Keywords: Vehicle emissions, Traffic waves, Autonomous vehicles, Traffic stability

\section{Introduction}

It is expected that in the next few years vehicles will be developed with enhanced automation capabilities, and soon autonomous vehicles (AVs) will begin entering the vehicle fleet in small numbers. Even at low penetration rates (e.g., as low as 5\% under ideal circumstances), these vehicles may be capable of dampening traffic waves caused by human driving behavior, resulting in smoother driving profiles (e.g., reduced acceleration/deceleration and speed variability) and consequently smoother traffic flow conditions compared to entirely human-piloted traffic [37]. Smooth driving profiles result in lower fuel consumption and emissions, which are damaging to the environment and to human health [13].

The main focus of this article is to quantify the potential reduction of vehicle emissions of the total traffic flow when a small fraction of vehicles are automated and designed to dampen humangenerated stop-and-go traffic. This work uses experimental traffic data collected during a series of experiments in which a single autonomous vehicle is carefully controlled to dampen stop-and-go waves that arise when human-piloted traffic is sufficiently dense [37]. The data used to assess the potential emissions impact of AVs stabilizing the traffic flow is found in the work by [37]. The primary contribution of the work by [37] was the design of controllers to dampen traffic waves.

The reduction in emissions of the total traffic flow are estimated from the experimental data using the MOtor Vehicle Emissions Model (MOVES) [15]. While the introduction of AVs at large penetration rates is certain to induce large effects such as changes in land use [24], travel demand [20], mode choice [26], and vehicle ownership [16], here we consider the impact that a small penetration rate of carefully controlled AVs can have on emissions due to the stability of the resulting traffic flow. By holding constant other large but longer term effects, we are able to highlight that the effects on the flow stability and consequently the emissions of the flow is itself significant (i.e., between $15 \%$ and $73 \%$ depending on the pollutant). To the best of our knowledge, this is the first of its kind study to use experimental data to demonstrate that that even at a low market penetration rate, the presence of AVs in the traffic flow may have the potential to reduce vehicle emissions of the overall traffic flow.

\subsection{Related work on air quality and vehicle emissions}

Motor vehicle emissions are a primary source of greenhouse gasses and contribute to global climate change [9]. These emissions are made worse by congestion and stop-and-go traffic [6]. Recently, a broad range of efforts have been made to curb vehicle emissions [35]. These efforts include vehicle improvements to increase the efficiency of combustion engines [31, 32] and a transition to hybrid vehicles $[18,12]$. It also includes traffic network management strategies that have focused on more efficient vehicle routing and traffic control $[48,7,43]$. It is anticipated that AVs will also 
impact vehicle emissions, though it is unclear whether they will increase or decrease overall traffic emissions $[10,36]$.

Direct measurement of vehicle emissions has been an area of intense research interest for several decades [33, 41, 19, 21]. However, due to the large cost associated with emissions measurement equipment, there has been a significant push [30, 29, 3] to develop models that are able to estimate vehicle emissions based on easier to measure quantities such as vehicle speed and acceleration. These models estimate the vehicle emissions for a variety of pollutants (e.g., carbon dioxide, carbon monoxide, hydrocarbons, and nitrogen oxides).

These emissions models generally fall into one of two categories: aggregate and microscopic. Aggregate models are used to assess the environmental impact during project planning and use inputs such as average link-level speed and distance traveled to assess emissions. These models are often useful for assessing the impact of a large change in land use and traffic patterns on city or regional emissions. Popular aggregate models include the US Environmental Protection Agency (EPA) MOVES [15] and MOBILE6 [14] as well as the European Environment Agency COPERT [25] and ARTEMIS [4] models. In contrast, microscopic emissions models use instantaneous measurements at the vehicle level to estimate emissions for a specific trip. Common microscopic emissions models include CMEM [3], EMIT [8], POLY [40], and VT-Micro [1, 29, 30]. These models are typically used for estimating emissions of individual vehicles under some specified drive cycle or test procedure.

The MOVES model offers both an aggregate analysis as discussed above as well as a vehiclespecific power (VSP) based analysis that allows for instantaneous emissions modelling at the individual vehicle level. It is a state-of-the-science emission modeling system that estimates emissions for mobile sources for air pollutants. The aggregate approach provided by MOVES estimates vehicle emissions based on a mapping between average travel speed and emission rates. The VSP-based approach estimates vehicle emissions by utilizing relationship between engine load and vehicle emissions at a high time-resolution $(1 \mathrm{~Hz})$, and is capable of assessing the influence of transient vehicle dynamics on engine load and emissions. Therefore, this approach is suitable to analyze vehicles emissions on an ad-hoc road link or segment as has been done in previous studies integrating vehicle travel profiles with the MOVES model to investigate air quality benefits of various traffic management or control technologies. For examples, see the works by [2, 46, 44], and [50]. In these studies, vehicle travel profiles were obtained through either traffic simulation or realworld data collection. Furthermore, the MOVES model is regularly maintained and updated by EPA to reflect emission characteristics and improvements of emissions control techniques future vehicles. The analysis in this article relies on emissions estimates from a VSP analysis conducted in MOVES.

\subsection{Related work on human-generated traffic waves and wave dampening}

Traffic waves are a common phenomenon on urban highways. They have been shown to arise even in the absence of external bottlenecks such as merges or reduction in lanes. This has been experimentally demonstrated by [38], where 22 vehicles drive on a ring-road track as well as by [39], who conduct similar experiments with between 10 and 40 vehicles. In both cases the vehicles begin with uniform speed and spacing, but the flow quickly devolves into a stop-and-go 
wave that travels upstream. These results have been independently validated in the experiments of [45] and [37], which replicated the [38] experimental design, and confirmed that human driving behavior alone is sufficient to trigger traffic instabilities such as stop-and-go waves. These traffic instabilities are often referred to as phantom jams [23] and can reduce the throughput and increase the fuel consumption of all vehicles on the roadway [37].

The ability of AVs to reduce emissions has been considered by several simulation-based works reviewed below [27, 47]. [27] modified a typical vehicle speed profile, and applied smoothing techniques to produce a plausible synthetic AV driving profile. The emissions estimates of both the original (oscillatory) and the smoothed velocity profile are compared using MOVES, and it is found that AV emissions may be substantially reduced. Compared to the present work, [27] do not consider field data captured from vehicles. Moreover, they only considers the direct benefits of a smooth driving profile on the emissions of the $\mathrm{AV}$, and do not capture the potential of AVs to also reduce the emissions of human piloted vehicles due to the smoother driving profile the AVs that may propagate to human drivers.

[47] propose a control framework to provide advisory speeds to a subset of vehicles with the goal to smooth the traffic flow. The framework is modeled in simulation at varying AV market penetration rates ranging from $1 \%$ to $100 \%$. Human-piloted traffic is simulated using a car-following model, and some vehicles implement a green driving strategy to dampen traffic waves a feedbackbased cooperative adaptive cruise control (CACC). The output from the simulation is analyzed using the CMEM model to estimate the fuel consumption and emissions. They find that at a $5 \%$ penetration rate of CACC-equipped vehicles in the traffic, hydrocarbon and carbon monoxide emissions are reduced by about $60 \%$, while carbon monoxide emissions are reduced by as much as $73 \%$ and carbon monoxide emissions are reduced by $9 \%$. In agreement with the experimental findings presented in this article, the simulation results of [47] indicate a reduction in emissions and fuel consumption is possible with the introduction of a small number (e.g., $~ 5 \%$ ) vehicles that actively dampen the traffic flow.

In contrast to enforcing specific speed profiles using AVs or ACC vehicles the ability of advisory speed limits to calm traffic and reduce emissions has also been studied. [34] study the use of an advisory speed to smooth traffic and quantify the effect of the advisory speed on vehicle emissions of the traffic flow. Using traffic simulation and the CMEM model, they study varying rates of vehicles that follow the advisory speed, and determine that while the advisory speed may not significantly impact the travel time, it can have a significant impact in reducing vehicle emissions and fuel consumption. [34] find a $35 \%$ reduction in carbon dioxide emissions, a $85 \%$ reduction in carbon monoxide emissions, a $69 \%$ reduction in hydrocarbon emissions, and a $74 \%$ reduction in nitrogen oxide emissions when all vehicles follow the advisory speed limit.

\subsection{Contribution and outline}

The works discussed above provide simulation results to give insight into the possible reduction in emissions that may result from even just a small portion of the vehicle fleet becoming autonomous. In contrast, this article uses experimental data from [37], to analyze the impact of a single AV on the vehicle emissions of all of the vehicles in the traffic flow. Thus, this work goes beyond the previously mentioned simulation results since it uses experimental data to demonstrate the ability 
of $\mathrm{AVs}$ to reduce emissions. While the experimental data used for this study consider a uniform AV penetration rate of roughly 5\%, higher AV penetration rates will likely be required for deployments of such systems on real freeways.

This article presents experimental evidence of the impact of oscillatory traffic on emissions, and quantifies the potential emissions reductions possible if the waves are mitigated using automated vehicles. This is accomplished by measuring vehicle trajectories in a series of experiments conducted by [37] on a circular ring road similar those of [38], and estimating the microscopic vehicle emissions using the VSP analysis in MOVES. The use of the ring road is experimentally beneficial since it allows for the isolation of car following behavior alone, without capturing confounding factors such as lane changing. Furthermore, three control strategies are implemented on a single AV in the flow of mostly human-piloted vehicles to control the flow and dampen traffic waves. The three control strategies give an indication of the variability of the potential benefits due to the implementation of the precise control law implemented by the AV. The reduction in emissions due to the control action of a single autonomous vehicle ( $\sim 5 \%$ of the traffic stream in the experiments) is presented in this article. To identify if the benefits observed are due to the vehicles used in the experiments, or if there will still be benefits in the future when the fleet mix changes, we consider four fleet scenarios that include the vehicle fleet tested in the experiments as well as projected fleets in the future. Full details of the four scenarios considered are presented in Table 1.

This work is part of a larger body of research that explores how traffic waves develop and the impacts of a small number of AVs actively dampening the traffic flow. This includes an article that presents a dataset with vehicle trajectories and a data collection methodology by [45] as well as work on the traffic flow implications of AVs [37]. The main contribution of this work is to quantify the reduction in total traffic emissions possible when a single autonomous vehicle in a flow of 20 to 21 human-piloted vehicles is driven to dampen the traffic waves present in the flow. We find that driving a single autonomous vehicle in such a way as to dampen traffic waves can reduce traffic emissions of the entire traffic flow between $15 \%$ and $73 \%$. The remainder of the article is organized as follows. We first present the design of the experiment to collect data using human drivers and an $\mathrm{AV}$, and discuss strategies to dampen traffic waves using an $\mathrm{AV}$ as well as review methods for estimating vehicle emissions in Section 2. The results are presented in Section 3 and we conclude that a small number $(\sim 5 \%)$ of AVs in the traffic flow may significantly reduce vehicle emissions for all vehicles on the roadway in Section 4.

\section{Methodology}

In this section, the methodology used in the experimental design and execution, as well as data analysis is discussed. First, we describe the experimental setup, next we describe the wavedampening controllers tested, and finally we briefly summarize the model used to estimate vehicle emissions. 


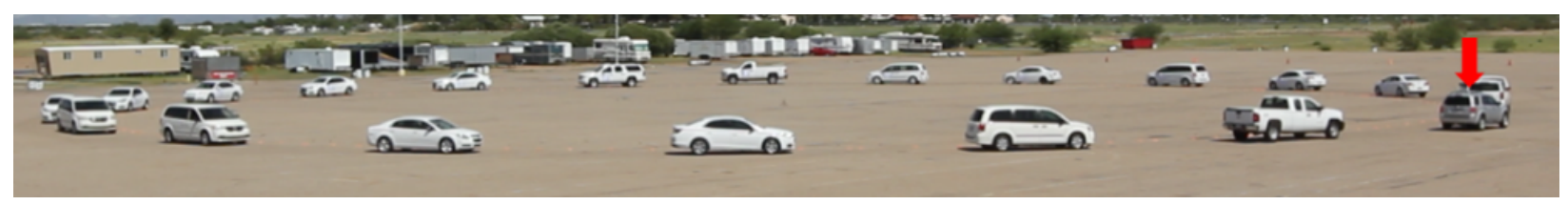

(a) Alignment of vehicles at start of Experiment A.

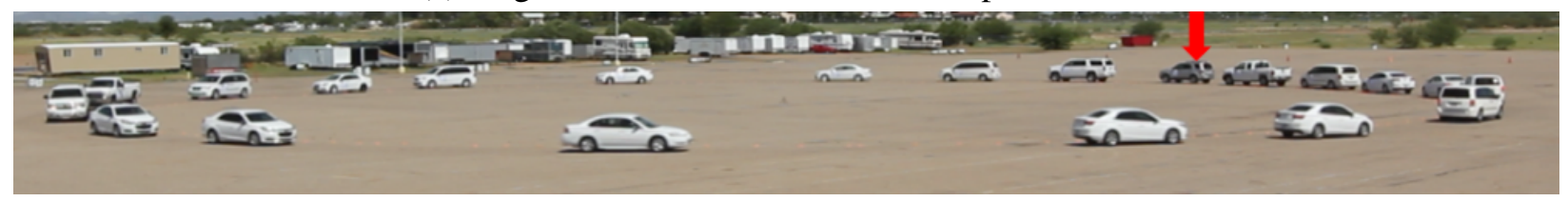

(b) Alignment of vehicles 95 seconds into Experiment A when wave is present in back right.

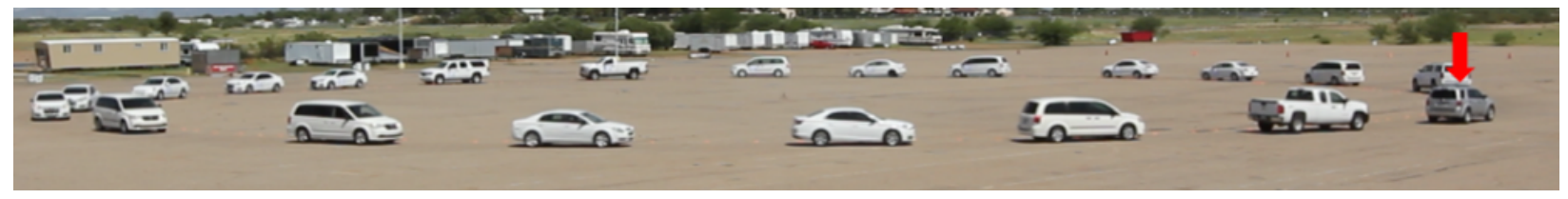

(c) Alignment of vehicles 328 seconds into Experiment A when the CAT Vehicle is actively dampening the wave.

Figure 1: Experimental track with 21 vehicles during Experiment A. The position of the CAT Vehicle is shown with a red arrow.

\subsection{Experimental setup}

The vehicle trajectories used to estimate vehicle emissions in this article are obtained from the experiments described in [37]. The experiments consist of between 21 and 22 vehicles driving on a single lane ring track, $82.8 \mathrm{~m}$ in diameter (260 m track length), located in a large parking lot in Tucson, AZ as seen in Figure 1. The experiments are designed to have a similar vehicle density as the experiment conducted by [38].

Vehicles are obtained from the University of Arizona motor pool, and are all recent model year passenger vehicles. At the beginning of each experiment, vehicles are spaced evenly on the track, with the number of vehicles between experiments varying from 21 to 22 vehicles depending on the desired density. Hired drivers are instructed to drive as they would in regular traffic, and to follow the vehicle in front of them safely. Individual tests last between 5 and 10 minutes, with breaks between to reset the track and allow for drivers to rest.

A single vehicle in the experiment, the University of Arizona's Cognitive and Autonomous Test (CAT) Vehicle, is a highly instrumented and actuated vehicle that can be switched from being human-piloted to autonomous. In each experiment, the CAT Vehicle begins under human control with a driver who is given the same instructions as all other drivers. Once traffic waves develop, the driving behavior of the CAT Vehicle is changed by either switching the CAT Vehicle into an autonomous driving mode (Experiments A and C), or by instructing the driver of the CAT Vehicle to drive with a specific velocity (Experiment B). These experiments allow data collection on traffic in which stop-and-go waves appear due to human driving behavior, and are subsequently dampened or eliminated via control of a single vehicle on the track, which represents a scenario 
in which roughly $5 \%$ of vehicles are either autonomous, or driving an a way that is substantially different from the human drivers. A brief overview of the experimental procedure is presented below.

1. Set vehicles on track at starting positions (even spacing)

2. Begin driving, all vehicles under human control

3. Intervene by instructing driver of CAT Vehicle to engage AV mode (Experiment A and C) or change driving behavior (Experiment B)

\section{End experiment, all vehicles come to rest}

The experiment is recorded by a 360-degree panoramic camera placed at the center of the circular track. Video recordings from the center 360-degree camera are used to extract vehicle trajectory data through computer vision algorithms. The computer vision algorithm uses background subtraction and pixel clustering, and template tracking to identify the position of each vehicle on the track in each frame. The resulting vehicle trajectories are verified against human-labeled data to an accuracy of $0.11 \mathrm{~m}$. The full data are provided by [37], and details of the algorithms used to process the data are provided by [45].

\subsection{Dampening traffic waves}

A total of three control approaches implemented on the CAT Vehicle are tested. All controllers share the goal to stabilize the entire traffic flow such that all vehicles, including the human-piloted vehicles, drive with as little velocity variation as possible. The general strategy employed by all three methods is to command the AV to drive with a properly selected velocity, and to drive with as uniform of a velocity profile as possible while still operating the vehicle safely. If this uniform velocity is close to the equilibrium velocity [11] of the traffic flow, the AV allows a small gap to open up as the vehicles race away when they exit a traffic wave, and is able to use this gap to avoid braking when the vehicles in front enter a traffic wave. While the equilibrium velocity may depend on a number of factors, practically, the local average speed may be used as a good approximation of the equilibrium velocity. This allows the AV to approach the lead vehicle just as it is leaving a traffic wave, and thus dampens the wave. The controllers that are run on the CAT Vehicle are briefly summarized in this section and a detailed explanation of the controllers used on the CAT Vehicle to dampen traffic waves is provided by [37].

\subsubsection{Controller A: FollowerStopper controller}

The premise of this controller is to command exactly the desired velocity whenever safe (i.e., as in a standard cruise controller), but to command a suitable lower velocity whenever safety requires, e.g., to avoid colliding with the lead vehicle. Using the gap to the lead vehicle (defined as the distance from the front bumper of the AV and the rear bumper of the lead vehicle) and the velocity difference between the lead vehicle and the AV, three regions are defined: (i) a safe region, where 
the AV drives at the desired speed, (ii) a stopping region, where a zero velocity is commanded, and (iii) an adaptation region, where some average of desired and lead vehicle velocity is commanded. These regions allow the AV to select a safe velocity, while driving as smoothly as possible. The full details on the calibration and implementation of the FollowerStopper controller are provided in the work by [37].

\subsubsection{Controller B: Traffic control with a trained human driver}

One experiment is conducted where a trained human driver is instructed to drive at a specified speed and only deviate when safety mandates. The speed at which the driver is instructed to drive is computed externally by experimental staff observing the experiment. It is computed as the total length of the track divided by the time for the CAT Vehicle to make one complete pass around the track. This speed is then communicated to the driver of the CAT Vehicle via two-way radio.

\subsubsection{Controller C: PI controller with saturation}

The idea behind this controller is that the CAT Vehicle may estimate the average speed of the vehicles in front, and drive as close to that average speed as safely possible. When stop-and-go waves are present, it allows a gap to open up in front of the CAT Vehicle when the lead vehicle accelerates, which is then closed when the lead vehicle decelerates as it enters the next wave. An estimate of the average speed required by the controller can be obtained through connectivity with other AVs in the flow ahead of the CAT Vehicle. The controller determines a command velocity for the AV following a standard proportional integral (PI) control logic where the deviation from the average speed is treated as the error signal in the PI controller. More information about the general structure of PI controllers can be found in [5]. The PI controller is modified to include a saturation effect, in which the CAT Vehicle should command the velocity of the lead vehicle for safety reasons when the gap is small.

\subsection{Estimating vehicle emissions}

In this work, the operating mode based project level analysis module in MOVES is used to evaluate vehicle emissions and assess emission benefits of replacing roughly $5 \%$ of the traffic flow with AVs that are specifically designed to stabilize the traffic flow. We adopt MOVES since the EPA regularly maintains and updates the MOVES model to reflect emissions characteristics and improvements in emission control technologies in new and future vehicles. This feature of MOVES is important since the scenarios we consider include the impacts that AVs may have both currently and in future years.

The MOVES model predicts vehicle emissions based on five different parameter values. These parameters are the humidity and temperature, the road link that the modelling is being conducted on, the vehicle fleet mix, the vehicle fleet age distribution, and the VSP distribution during the drive cycle. These parameters are explained in more detail below.

1. Humidity and Temperature: Meteorological conditions influence vehicle engine performance and thus will effect vehicle emissions. The simulation time and location are set to the same 
as the experiment time and experiment location: Tucson, Arizona in July. This takes into account average high temperatures and precipitation in Tucson, Arizona in July.

2. Road Link: We assume each experiment is one road link. The length of each road link is computed as the average distance each vehicle drove during the experiment. It is important to note that since the total emissions on that road link are normalized by the length of the road link, the link length does not impact emission rates per distance, but does impact the total emissions of the fleet on the link.

3. Vehicle fleet mix: In this study, we only consider the light-duty vehicle fleet, which consists of sedans and light-duty trucks (e.g., SUVs and small pickup trucks). These two types of vehicle are different in size, weight, engine capacity, etc., and therefore have different emission characteristics. The vehicle fleet mix used in this study is either the actual fleet mix used to experimentally collect the vehicle trajectories (Scenario 1 discussed in Section 2.4) or based on fleet mix projections (Scenarios 2-4) as discussed in Section 2.4.

4. Vehicle fleet age distribution: Emissions of vehicles vary based on age of vehicles due to an effect known as emissions deterioration [49]. Specifically, emissions per distance tend to increase as vehicles age. Therefore, it is important to know the age distribution of vehicle fleet to account for aging effect in our emission analysis. We adopted the default age distribution in MOVES, which specifies vehicle age distribution projections through the year 2050. The MOVES model assumes a distribution between 0 and 30 years of age.

5. VSP Distribution: For each experiment, the instantaneous velocity and acceleration is obtained from the experiments by [37]. Using these measurements, the corresponding VSP is calculated at $1 \mathrm{~Hz}$ VSP and then aggregated to obtain VSP distribution over time. For typical light-duty vehicles and trucks, VSP in units of $\mathrm{kW} /$ ton can be approximated using (1) where $v$ is the vehicle velocity in $\mathrm{mph}, a$ is the vehicle acceleration in $\mathrm{mph} / \mathrm{s}$. This equation models work required due to acceleration of the mass of the vehicle, rolling friction, and air drag, but does not consider non-driving related energy consumption such as air conditioning.

$$
\mathrm{VSP} \approx \phi_{1} v a+\phi_{2} v+\phi_{3} v^{3}
$$

where $\phi_{1}=0.22, \phi_{2}=0.0954, \phi_{3}=0.0000272$ [22]. Using this approximation for all vehicles neglects small differences in air resistance due to vehicle form or rolling resistance due to tire pressure.

\subsection{Vehicle fleet scenarios considered}

The effect on vehicle emissions of a small number of AVs in the traffic flow will depend to a large extent on the vehicle fleet on the road, and the levels of emissions they produce. Therefore, a total of four scenarios with different fleets are considered. These scenarios use the same experimentally-collected vehicle trajectories for all scenarios and represent different vehicle fleet mixes as described below. These scenarios are detailed in Table 1. 


\begin{tabular}{c|ccc}
\hline Scenario & Electric vehicle fraction (\%) & Sedan fraction $(\%)$ & Small truck fraction (\%) \\
\hline 1 & 0.0 & 45.5 & 54.5 \\
2 & 0.0 & 51.2 & 48.8 \\
3 & 3.4 & 44.5 & 55.6 \\
4 & 80.0 & 42.8 & 57.2 \\
\hline
\end{tabular}

Table 1: Four scenarios considered including 1) the vehicle fleet tested in the 2016 experiment, 2) US national vehicle fleet in 2016, 3) the projected 2030 vehicle fleet, and 4) the projected 2050 vehicle fleet, assuming an $80 \%$ vehicle electrification, spread evenly across both vehicle classes.

In Scenario 1, the vehicle fleet used during the experiments is considered, where $45.5 \%$ of the vehicles are sedans, $54.5 \%$ are SUVs, and no electric vehicles (EVs) are present. In Scenario 2, the average 2016 vehicle fleet in the US is considered where $51.2 \%$ of the vehicles are sedans, $48.8 \%$ are SUVs, and a negligible percentage of the vehicles are electrified. Scenario 3 considers the projected 2030 vehicle fleet in the US where $44.5 \%$ of the vehicles are sedans and an estimated $3.4 \%$ of the vehicle fleet is electrified, distributed evenly between sedans and SUVs, as projected by the US Energy Information Administration's 2017 Annual Energy Outlook [42]. Finally, in Scenario 4 the projected 2050 vehicle fleet in the US is considered with $42.8 \%$ sedans assuming a very high electric vehicle adoption rate of $80 \%$. This fleet also takes into account the vehicle age distribution for Scenarios 2, 3, and 4, while the vehicle age distribution in Scenario 1 is obtained from the vehicle fleet used to conduct the experiments.

\section{Experimental results}

For completeness we briefly describe the three traffic experiments that are conducted. A full description of the experimental setup is provided in Section 2. The goal of the experiments is to demonstrate the ability of a single AV to dampen traffic waves that naturally occur from human driving behavior. A total of three wave-dampening strategies are used in the three ring road experiments.

The vehicles can be seen on the track at various stages in the experiment in Figure 1. Specifically, in Figure 1a, the vehicles are observed with uniform spacing at the start of the experiment. After $95 \mathrm{~s}$, a stop-and-go wave is present in the traffic flow and the configuration of vehicles on the ring road is seen in Figure 1b. Finally, when the AV is actively dampening the traffic flow, the uniform traffic flow $328 \mathrm{~s}$ after the start of the experiment is seen in Figure 1c.

In Experiment A, the FollowerStopper controller is used to dampen traffic waves, while in Experiment B a human driver is instructed to drive the CAT Vehicle at a constant speed, and in Experiment $\mathrm{C}$ a PI controller with saturation is used to dampen traffic waves. In all experiments, the result of the control algorithm is to reduce the velocity standard deviation as seen in the vehicle trajectories in Figures 2, 3, and 4 for Experiments A, B, and C, respectively. Summary statistics of each experiment are provided in Table 2.

Vehicle emissions rates for hydrocarbons $(\mathrm{HC})$, carbon monoxide $(\mathrm{CO})$, carbon dioxide $\left(\mathrm{CO}_{2}\right)$, 


\begin{tabular}{c|ccc}
\hline Experiment & Total time (s) & Avg. speed no control (m/s) & Avg. speed with control (m/s) \\
\hline A & 567 & 6.33 & 7.04 \\
B & 409 & 6.29 & 6.86 \\
C & 413 & 6.05 & 5.57 \\
\hline
\end{tabular}

Table 2: Experiment summary statistics.
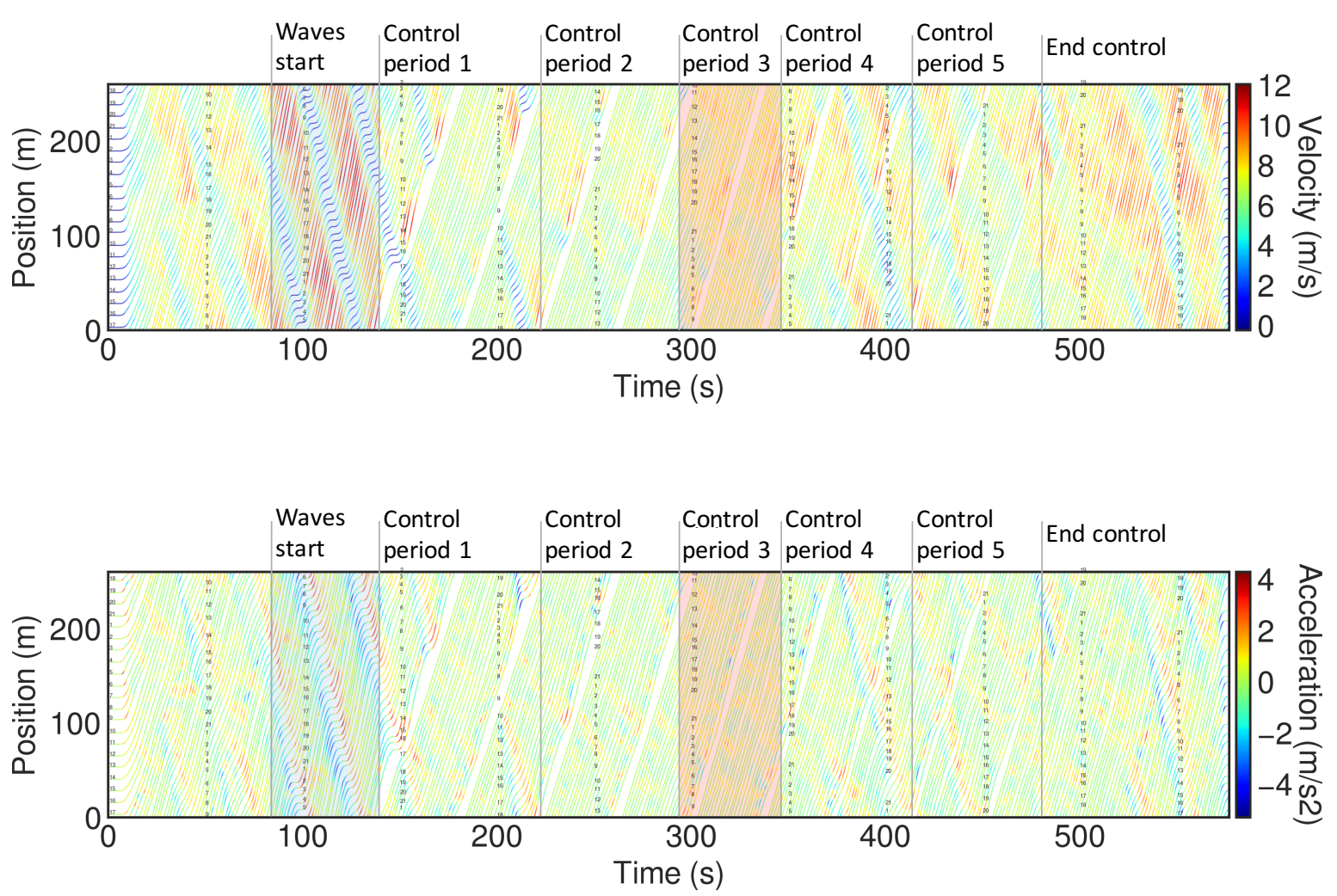

Figure 2: Vehicle trajectories for all vehicles in Experiment A color coded by, velocity (top), and acceleration (bottom). The time under which traffic waves are present is shaded blue, while the control period used for analysis, where the AV is actively dampening traffic waves is shaded red. 

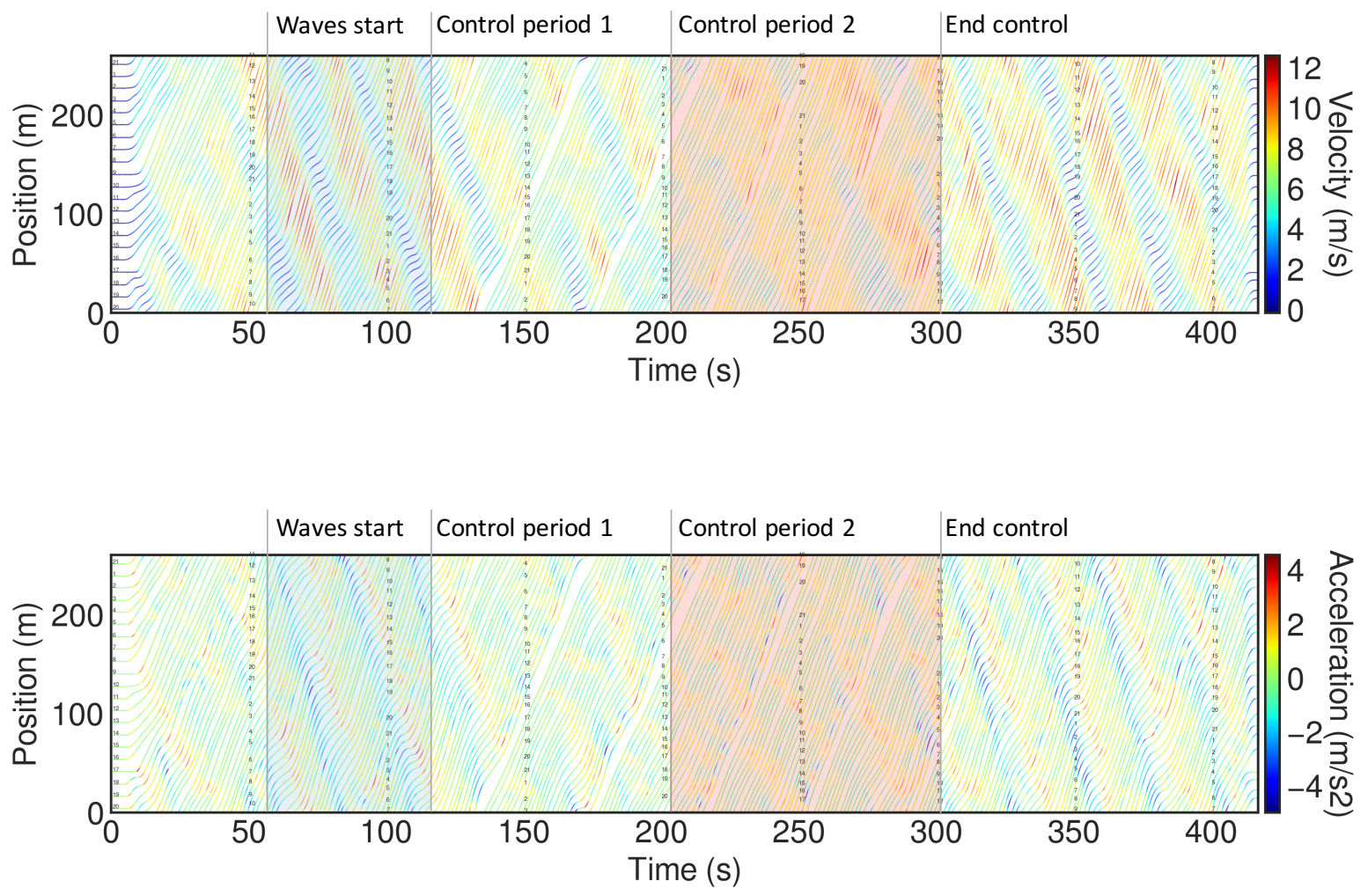

Figure 3: Vehicle trajectories for all vehicles in Experiment B color coded by, velocity (top), and acceleration (bottom). The time under which traffic waves are present is shaded blue, while the control period used for analysis, where the AV is actively dampening traffic waves is shaded red. 

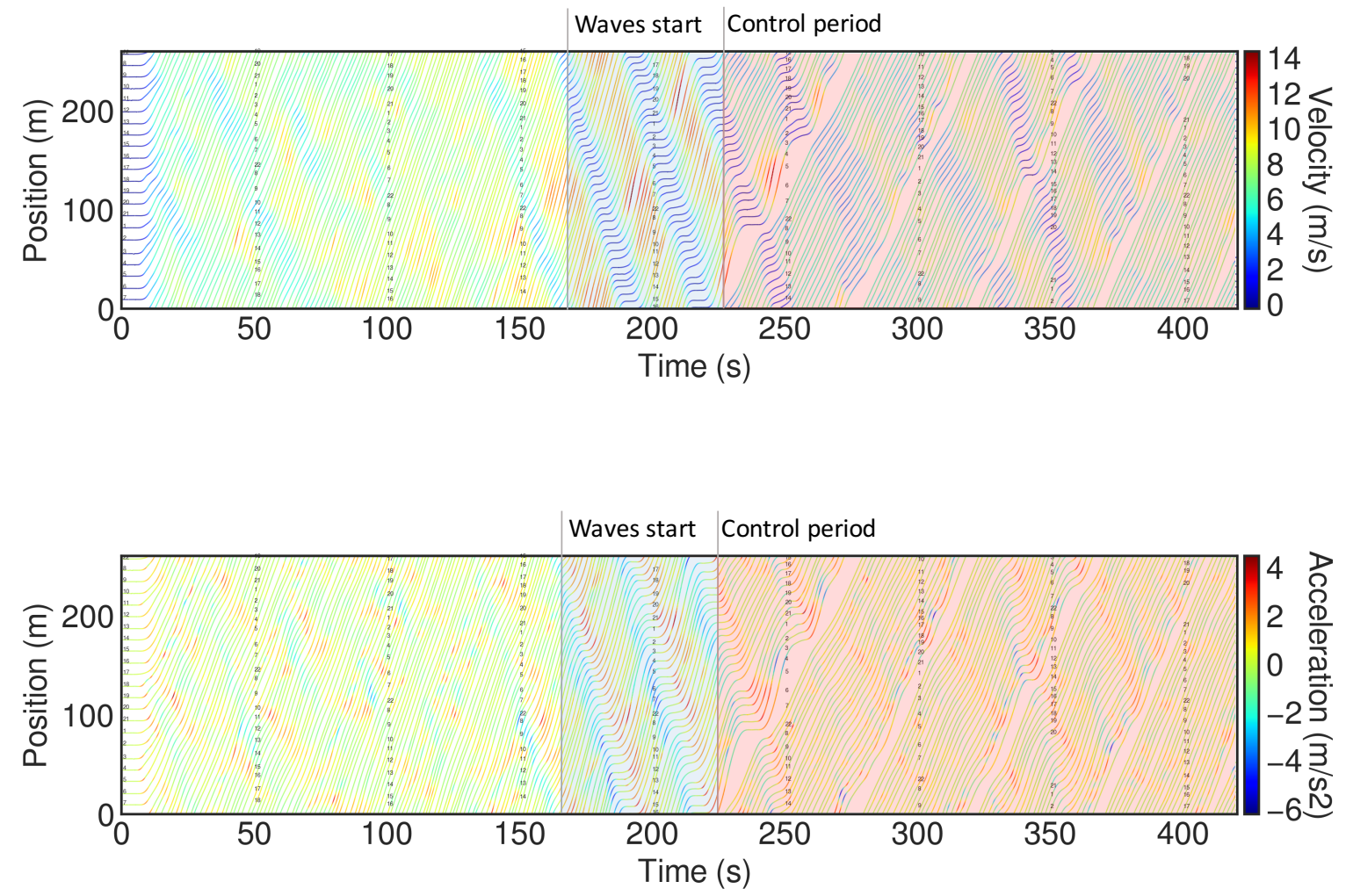

Figure 4: Vehicle trajectories for all vehicles in Experiment $\mathrm{C}$ color coded by, velocity (top), and acceleration (bottom). The time under which traffic waves are present is shaded blue, while the control period used for analysis, where the AV is actively dampening traffic waves is shaded red. 
and nitrogen oxides $\left(\mathrm{NO}_{\mathrm{x}}\right)$ are obtained through MOVES for each of the three experiments. While there are several controller periods tested in each experiment, for the purposes of this analysis only the period when waves are present and the period where the AV controller is most effective are used.

\subsection{MOVES operating mode distribution}

The MOVES analysis is based on the percentage of time in each drive schedule that is spent in a particular operating mode. These operating modes are specified by defining specific ranges of speed and VSP. Consequently, it is possible to classify each moment of the drive schedule as one of a number of discrete operating modes, which correspond to vehicle emissions. Specifically, the percent of time spent in each operating mode over the course of a drive schedule along with the total distance traveled and the average travel speed determine the vehicle emissions estimate. The operating modes are outlined in the MOVES documentation [15].

The operating mode distributions for each experiment are separated for the period when traffic waves are present and the period when the AV is actively dampening the traffic flow, and plotted in Figures 5a through 5c. A greater percentage of the time is spent in higher operating modes when waves are present than when the AV is actively dampening the waves.

As seen in Figure 5a through Figure 5c, when comparing the MOVES operating mode distribution under uncontrolled conditions when traffic waves are present (left) to the operating mode distribution when the CAT Vehicle is actively dampening the traffic flow (right), the operating mode distribution shifts from higher operating modes to lower operating modes. These lower operating modes are indicative of lower engine demand, and thus generally correspond to lower vehicle emissions. This is because there is less positive acceleration across the vehicle fleet when the CAT Vehicle is actively dampening the traffic flow, and thus lower VSP. Note that these distributions do not change under the scenarios considered.

\subsection{Scenario 1: Estimating emissions of the experiment fleet}

We estimate the emissions of the experimental fleet as tested in three different experiments. We consider the reduction of emissions when a single vehicle in the traffic flow is an AV, and consider three different control strategies, one in each of the three experiments. In Experiment A, the average per-vehicle emissions in the experiment (Scenario 1) in the presence of traffic waves for hydrocarbons is $0.010 \mathrm{~g} / \mathrm{mi}$, for carbon monoxide are $2.430 \mathrm{~g} / \mathrm{mi}$, for nitrogen oxides are 0.107 $\mathrm{g} / \mathrm{mi}$, and for carbon dioxide are $1245 \mathrm{~g} / \mathrm{mi}$. When the traffic is under the control of the AV in the control period when the set speed is $7.50 \mathrm{~m} / \mathrm{s}$, the hydrocarbon emissions are reduced by $51.5 \%$ to $0.005 \mathrm{~g} / \mathrm{mi}$, the carbon monoxide emissions are reduced by $39.1 \%$ to $1.481 \mathrm{~g} / \mathrm{mi}$, the nitrogen oxide emissions are reduced by $73.5 \% 0.028 \mathrm{~g} / \mathrm{mi}$, and the carbon dioxide emissions are reduced by $30.7 \%$ to $863.1 \mathrm{~g} / \mathrm{km}$.

In Experiment B, the average per-vehicle emissions when a traffic wave is present in the vehicle fleet tested in the experiment (Scenario 1) are as follows: hydrocarbon emissions are 0.010 $\mathrm{g} / \mathrm{mi}$, carbon monoxide emissions are $2.380 \mathrm{~g} / \mathrm{mi}$, nitrogen oxide emissions are 0.095 and the carbon dioxide emissions are $1260 \mathrm{~g} / \mathrm{mi}$. When the AV is actively dampening the traffic waves, the 

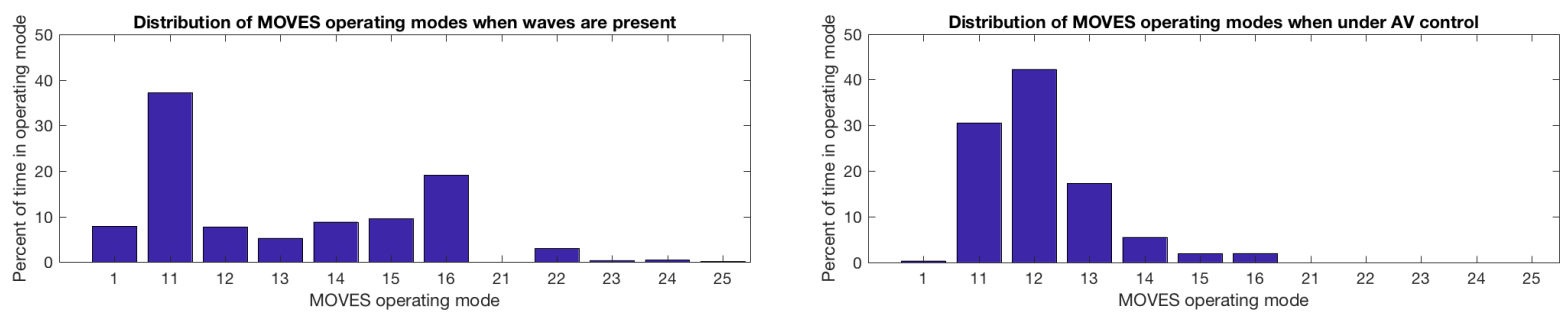

(a) Distribution of MOVES operating modes in Experiment A.
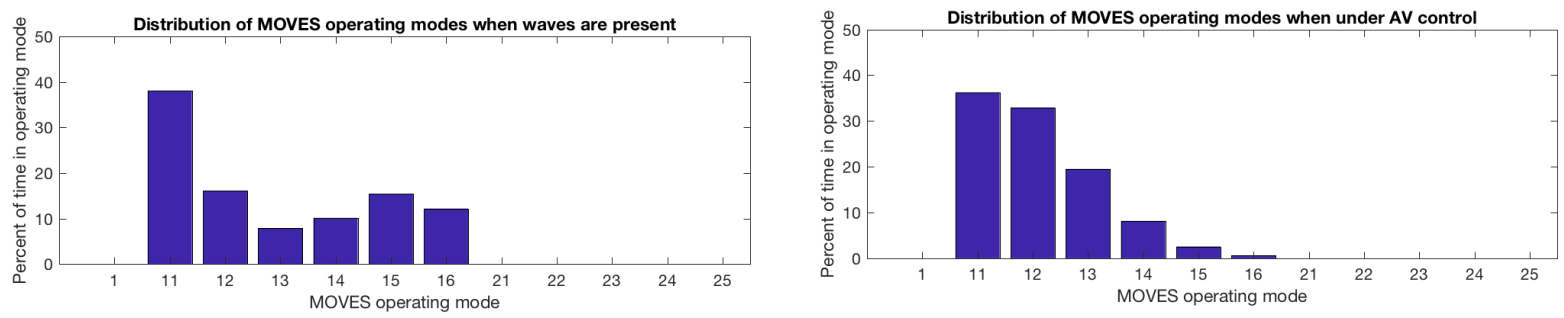

(b) Distribution of MOVES operating modes in Experiment B.
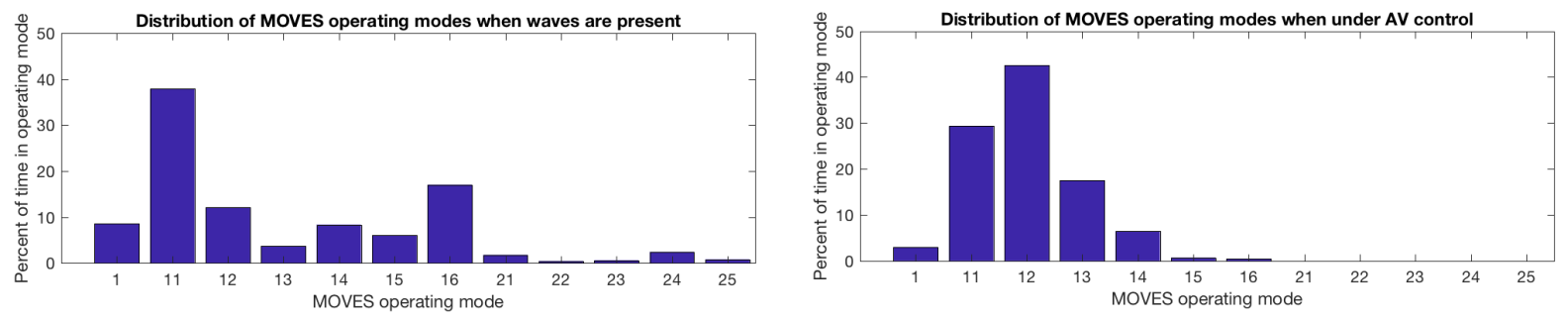

(c) Distribution of MOVES operating modes in Experiment C.

Figure 5: Distribution of MOVES operating modes in each of the three experiments when waves are present (left) and when the AV is actively dampening the traffic waves (right). Note that while the MOVES model defines operating modes above 25, these operating modes are not observed in any of the experiments, and thus left off of these figures for plotting purposes. Additionally, note that these distributions are applicable to all scenarios. 
hydrocarbon emissions are reduced by $38.7 \%$ to $0.006 \mathrm{~g} / \mathrm{mi}$, the carbon monoxide emissions are reduced by $36.1 \%$ to $1.520 \mathrm{~g} / \mathrm{mi}$, the nitrogen oxide emissions are reduced by $60.8 \%$ to $0.037 \mathrm{~g} / \mathrm{mi}$, and the carbon dioxide emissions are reduced by $27.2 \%$ to $916.0 \mathrm{~g} / \mathrm{mi}$.

In Experiment $\mathrm{C}$, the average per-vehicle emissions in the presence of a traffic wave for Scenario 1 is $0.101 \mathrm{~g} / \mathrm{mi}$ for hydrocarbons, $2.420 \mathrm{~g} / \mathrm{mi}$ for carbon monoxide, $0.101 \mathrm{~g} / \mathrm{mi}$ for nitrogen oxides, and $1240 \mathrm{~g} / \mathrm{mi}$ for carbon dioxide. When the AV is actively dampening the traffic flow hydrocarbon emissions are reduced by $63.8 \%$ to $0.006 \mathrm{~g} / \mathrm{mi}$, carbon monoxide emissions are reduced by $26.9 \%$ to $1.770 \mathrm{~g} / \mathrm{mi}$, nitrogen oxide emissions are reduced by $63.3 \%$ to $0.037 \mathrm{~g} / \mathrm{mi}$, and carbon dioxide emissions are reduced by $14.8 \%$ to $1060 \mathrm{~g} / \mathrm{mi}$. The results can also be seen in Tables 3 through 6.

\subsection{Scenario 2: Emissions of the 2016 vehicle fleet}

In Scenario 2 which represents the average US fleet in 2016, the average per-vehicle emissions in Experiment A in the presence of traffic waves are $0.191 \mathrm{~g} / \mathrm{mi} \mathrm{HC}, 7.843 \mathrm{~g} / \mathrm{mi} \mathrm{CO}, 0.933 \mathrm{~g} / \mathrm{mi} \mathrm{NO}_{\mathrm{x}}$, and $1413 \mathrm{~g} / \mathrm{mi} \mathrm{CO} 2$. When the AV is actively dampening the traffic flow, the $\mathrm{HC}$ emissions are reduced by $38.4 \%$ to $0.125 \mathrm{~g} / \mathrm{mi}$, the $\mathrm{CO}$ emissions are reduced by $38.1 \%$ to $4.854 \mathrm{~g} / \mathrm{mi}$, the $\mathrm{NO}_{\mathrm{x}}$ emissions are reduced by $64 \%$ to $0.336 \mathrm{~g} / \mathrm{mi}$, and the $\mathrm{CO} 2$ emissions are reduced by $31.4 \%$ to 970 $\mathrm{g} / \mathrm{mi}$.

In Experiment B, in the presence of a traffic wave the average per-vehicle $\mathrm{HC}$ emissions are $0.189 \mathrm{~g} / \mathrm{mi}$, the average carbon monoxide emissions are $7.740 \mathrm{~g} / \mathrm{mi}$, the average nitrogen oxide emissions are $0.872 \mathrm{~g} / \mathrm{mi}$, and the average carbon dioxide emissions are $1420 \mathrm{~g} / \mathrm{mi}$. When the $\mathrm{AV}$ is actively dampening the traffic waves hydrocarbon emissions are reduced by $28.0 \%$ to 0.136 $\mathrm{g} / \mathrm{mi}$, carbon monoxide emissions are reduced by $34.6 \%$ to $5.060 \mathrm{~g} / \mathrm{mi}$, nitrogen oxide emissions are reduced by $53.0 \%$ to $0.411 \mathrm{~g} / \mathrm{mi}$, and carbon dioxide emissions are reduced by $27.5 \%$ to 1030 $\mathrm{g} / \mathrm{mi}$.

In Experiment $\mathrm{C}$, when traffic waves are present the average per-vehicle hydrocarbon emissions are $0.191 \mathrm{~g} / \mathrm{mi}$, the carbon monoxide emissions are $7.760 \mathrm{~g} / \mathrm{mi}$, the nitrogen oxide emissions are $0.884 \mathrm{~g} / \mathrm{mi}$, and the carbon dioxide emissions are $1410 \mathrm{~g} / \mathrm{mi}$. When the AV is actively dampening traffic waves hydrocarbon emissions are reduced by $17.8 \%$ to $0.157 \mathrm{~g} / \mathrm{mi}$, carbon monoxide emissions are reduced by $24.7 \%$ to $5.840 \mathrm{~g} / \mathrm{mi}$, nitrogen oxide emissions are reduced by $52.0 \%$ to $0.424 \mathrm{~g} / \mathrm{mi}$, and carbon dioxide emissions are reduced by $15.5 \%$ to $1190 \mathrm{~g} / \mathrm{mi}$. The results can also be seen in Tables 3 through 6 .

Figures $6 \mathrm{a}$ through $6 \mathrm{~d}$ show that the hydrocarbon, carbon monoxide, and nitrogen oxide emissions for Scenario 2 are substantially higher than in Scenario 1. This is because the vehicle fleet used in Scenario 1 was mostly 2016 and 2015 model year vehicles (full details on the vehicles used can be found in [37]) while Scenario 2 is composed of the US age distribution of vehicles in 2016. Since most of the vehicles are less than three years old, very little emissions deterioration has occurred, and the estimated emissions for that scenario were very low. Scenarios 2 through 4 use projected fleet age distributions, which assume a mix of new and old vehicles on the road. In the scenarios tested, the older vehicles may be polluting more than the newer vehicles due to emissions deterioration. This is not the case in the vehicle fleet tested in the 2016 experiment since most vehicles are new. 


\subsection{Scenarios 3 and 4: Emissions of projected future fleets}

The projected future vehicle fleet scenarios presented in Table 1 are also considered. The emissions for these scenarios are presented below. In Scenario 3, the projected 2030 US vehicle fleet us used for estimation. In Experiment $\mathrm{A}, \mathrm{B}$, and $\mathrm{C}$ the hydrocarbon emissions in the presence of traffic waves are $0.019 \mathrm{~g} / \mathrm{mi}, 0.018 \mathrm{~g} / \mathrm{mi}$, and $0.019 \mathrm{~g} / \mathrm{mi}$, respectively. When the Autonomous vehicle is actively dampening the traffic waves, the reductions in hydrocarbon emissions for Experiments A, $\mathrm{B}$, and $\mathrm{C}$ are $38.4 \%$ to $0.010 \mathrm{~g} / \mathrm{mi}, 37.8 \%$ to $0.011 \mathrm{~g} / \mathrm{mi}$, and $35.1 \%$ to $0.012 \mathrm{~g} / \mathrm{mi}$, respectively. Similarly, for Experiments A, B, and C, the carbon monoxide emissions in the presence of traffic waves are $2.984 \mathrm{~g} / \mathrm{mi}, 2.920 \mathrm{~g} / \mathrm{mi}$, and $2.960 \mathrm{~g} / \mathrm{mi}$, respectively. When the AV is actively dampening the traffic flow, carbon monoxide emissions are reduced by $39.3 \%, 36.1 \%$, and $27.1 \%$ to 1.812 $\mathrm{g} / \mathrm{mi}, 1.860 \mathrm{~g} / \mathrm{mi}$, and $2.160 \mathrm{~g} / \mathrm{mi}$ for Experiments A, B, and C, respectively. In the presence of a traffic wave, the nitrogen oxide emissions for Experiments $\mathrm{A}, \mathrm{B}$, and $\mathrm{C}$ are $0.114 \mathrm{~g} / \mathrm{mi}, 0.101$ $\mathrm{g} / \mathrm{mi}$, and $0.107 \mathrm{~g} / \mathrm{mi}$, respectively. By actively dampening the traffic flow, the AV is able to reduce the average vehicle emissions for Experiments A, B, and C by $72.5 \%, 59.8 \%$, and $61.0 \%$ to 0.031 $\mathrm{g} / \mathrm{mi}, 0.041 \mathrm{~g} / \mathrm{mi}$, and $0.041 \mathrm{~g} / \mathrm{mi}$, respectively. Finally, when traffic waves are present, the average per-vehicle emissions of carbon dioxide for Experiments A, B, and C are $1019 \mathrm{~g} / \mathrm{mi}, 1030 \mathrm{~g} / \mathrm{mi}$, and $1010 \mathrm{~g} / \mathrm{mi}$, respectively. When the AV is actively dampening the traffic flow, these are reduced by $31.0 \%, 27.3 \%$, and $15.1 \%$ to $703.0 \mathrm{~g} / \mathrm{mi}, 748.0 \mathrm{~g} / \mathrm{mi}$, and $15.1 \mathrm{~g} / \mathrm{mi}$, respectively.

In Scenario 4, the projected average US vehicle fleet for 2050 is used for estimation. However, a high electric vehicle adoption rate of $80 \%$ electric vehicles is also assumed. This is to test how significant the impact of AVs dampening the traffic flow will be on emissions with a high vehicle fleet electrification rate. When traffic waves are present, the average per-vehicle hydrocarbon emissions rate for Experiments A, B, and C, respectively are $0.003 \mathrm{~g} / \mathrm{mi}, 0.003 \mathrm{~g} / \mathrm{mi}$, and 0.003 $\mathrm{g} / \mathrm{mi}$. When the AV is actively dampening the traffic flow, these are reduced by $51.6 \%, 38.7 \%$, and $36.8 \%$ to $0.002 \mathrm{~g} / \mathrm{mi}, 0.002 \mathrm{~g} / \mathrm{mi}$, and $0.002 \mathrm{~g} / \mathrm{mi}$, respectively. The carbon monoxide emissions in the presence of traffic waves are $0.503 \mathrm{~g} / \mathrm{mi}, 0.491 \mathrm{~g} / \mathrm{mi}$, and $0.500 \mathrm{~g} / \mathrm{mi}$, for Experiments $\mathrm{A}, \mathrm{B}$, and $\mathrm{C}$, respectively. When the $\mathrm{AV}$ is dampening the traffic waves, the carbon monoxide emissions are reduced by $39.3 \%, 36.2 \%$, and $27.1 \%$ to $0.305 \mathrm{~g} / \mathrm{mi}, 0.314 \mathrm{~g} / \mathrm{mi}$, and $0.364 \mathrm{~g} / \mathrm{mi}$, for Experiments $\mathrm{A}, \mathrm{B}$, and $\mathrm{C}$, respectively. When a traffic wave is present, the average per-vehicle nitrogen oxide emissions for Experiments $\mathrm{A}, \mathrm{B}$, and $\mathrm{C}$ are $0.006 \mathrm{~g} / \mathrm{mi}, 0.005 \mathrm{~g} / \mathrm{mi}$, and $0.005 \mathrm{~g} / \mathrm{mi}$. These are reduced by $73.6 \%, 60.8 \%$, and $63.4 \%$ to $0.002 \mathrm{~g} / \mathrm{mi}, 0.002 \mathrm{~g} / \mathrm{mi}$, and $0.002 \mathrm{~g} / \mathrm{mi}$, for experiments $\mathrm{A}, \mathrm{B}$, and $\mathrm{C}$, respectively, when the $\mathrm{AV}$ is actively dampening traffic waves. Finally, in when traffic waves are present the carbon dioxide emissions are $246.7 \mathrm{~g} / \mathrm{mi}, 249.0 \mathrm{~g} / \mathrm{mi}$, and $245.0 \mathrm{~g} / \mathrm{mi}$, for Experiments A, B, and C, respectively. When the AV is actively dampening the traffic flow, the carbon dioxide emissions are reduced by $31.0 \%, 27.3 \%$ and $15.1 \%$ to $179.2 \mathrm{~g} / \mathrm{mi}, 181.0 \mathrm{~g} / \mathrm{mi}$, and $208.0 \mathrm{~g} / \mathrm{mi}$, for Experiments A, B, and C, respectively. The results for Scenarios 3 and 4 can also be seen in Tables 3 through 6.

The trend observed in Figures 6a through $6 \mathrm{~d}$ is a decrease in per-vehicle emissions both when waves are present and when the AV is actively dampening the traffic waves. This reflects the anticipated stringent emissions requirements in the future. When considering Scenario 4 where the projected 2050 vehicle fleet with an assumed $80 \% \mathrm{EV}$ market penetration rate is used for estimation, the reduction in average per-vehicle emissions rate has two sources: the increased 


\begin{tabular}{c|cccc|cccc|cccc}
\hline & \multicolumn{4}{|c|}{$\begin{array}{c}\text { Experiment A } \\
\text { (\% reduction) }\end{array}$} & \multicolumn{3}{c|}{$\begin{array}{c}\text { Experiment B } \\
\text { (\% reduction) }\end{array}$} & \multicolumn{4}{c}{$\begin{array}{c}\text { Experiment C } \\
\text { (\% reduction) }\end{array}$} \\
Scenario: & 1 & 2 & 3 & 4 & 1 & 2 & 3 & 4 & 1 & 2 & 3 & 4 \\
\hline $\mathrm{HC}$ & 51.5 & 38.4 & 50.4 & 51.6 & 38.7 & 28.0 & 37.8 & 38.7 & 36.8 & 17.8 & 35.1 & 36.8 \\
$\mathrm{CO}$ & 39.1 & 38.1 & 39.3 & 39.3 & 36.1 & 34.6 & 36.1 & 36.1 & 26.9 & 24.7 & 27.1 & 27.1 \\
$\mathrm{NO}_{\mathrm{x}}$ & 73.5 & 64.0 & 72.5 & 73.6 & 60.8 & 52.9 & 59.8 & 60.8 & 63.3 & 52.0 & 61.9 & 63.4 \\
$\mathrm{CO}_{2}$ & 30.7 & 31.4 & 31.0 & 31.0 & 27.2 & 27.5 & 27.3 & 27.3 & 14.8 & 15.5 & 15.1 & 15.1 \\
\hline
\end{tabular}

Table 3: Percent reduction in emissions from period with waves to period when the AV is actively dampening the traffic.

efficiency of combustion engines and the electrification of the fleet, which in Scenario 4 assumes that $80 \%$ of the vehicles have zero tailpipe emissions. This is also true to a lesser extent in Scenario 3 where the 2030 vehicle fleet with a projected $3.4 \% \mathrm{EV}$ penetration rate is assumed.

The experimental results for average per-vehicle emissions rates in Tables 4 through 6 are also represented graphically in Figure 6. These results show that in all three experiments (A, B, and C) the emissions rate in the presence of a wave is very similar. This indicates that in all three experiments, similar traffic conditions are observed as seen in Figures 2 through 4. Furthermore, while the details of the specific controllers used in Experiments A, B, and C are different, they all have a similar effect on reducing the emissions rate in each of the thee experiments for each fleet scenario, indicating that there is a variety of possible controllers that may be able to achieve similar reductions in vehicle emissions caused by stop-and-go traffic.

When looking at the emissions reduction, we observe that the emissions reduction for each emissions category is approximately the same across the different scenarios for each experiment. Thus, while the overall emissions are expected to reduce dramatically (Figures 6a through 6d), the impact that a low penetration rate of autonomous vehicles has on the traffic stream remains approximately unchanged.

Interestingly, as seen in Table 3, the percent reduction in $\mathrm{NO}_{\mathrm{x}}$ emissions is substantially greater than the percent reduction in other quantities across all scenarios and experiments. This is because high $\mathrm{NO}_{\mathrm{x}}$ emissions are correlated with transient engine behavior, while $\mathrm{CO}$ and $\mathrm{CO}_{2}$ emissions are correlated more closely to the fuel burn rate [28].

\section{Conclusions}

The results presented in this article indicate that a single autonomous vehicle can have a substantial impact on reducing traffic emissions if properly controlled to dampen traffic waves and stabilize the traffic flow. While a single autonomous vehicle out of 22 vehicles is autonomous in the experiments presented in this article, this should be thought of as a uniform AV penetration rate of roughly 5\%. These results represent the reduction in vehicle emissions that is possible due to the smoother traffic flow that may result from AVs dampening traffic waves, and the impact this has on the underlying traffic dynamics. These results are based on experimental data that is collected in a controlled environment to isolate the wave-amplifying car following behavior of human drivers in the absence of lane changing or other external factors. 


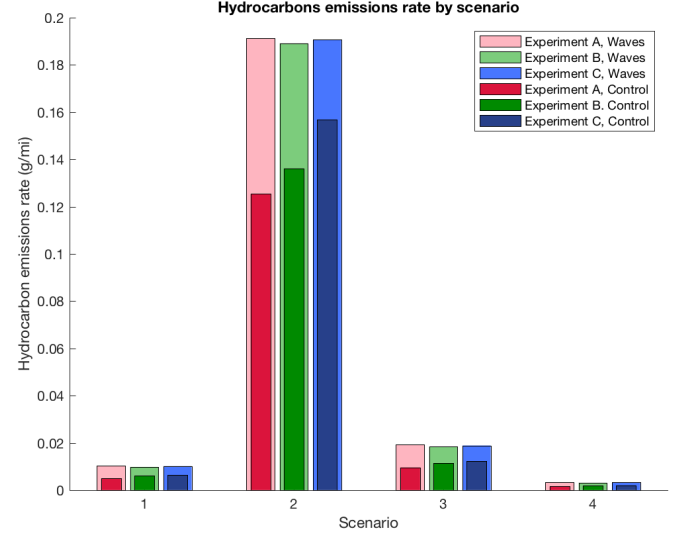

(a) Hydrocarbon emissions rate.

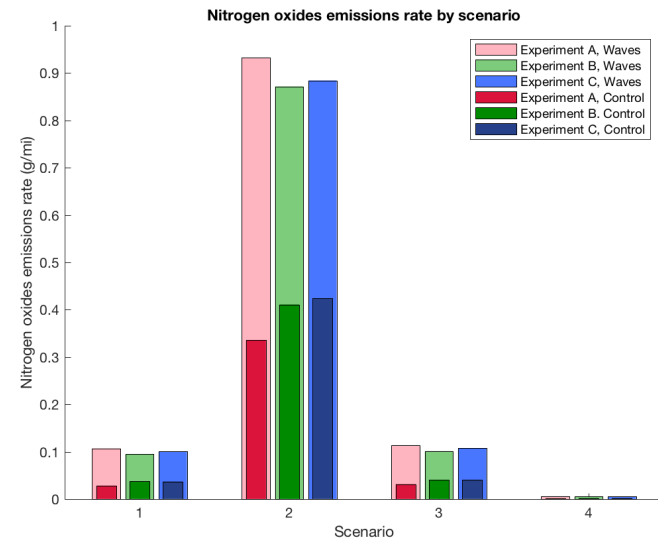

(c) Nitrogen oxides emissions rate.

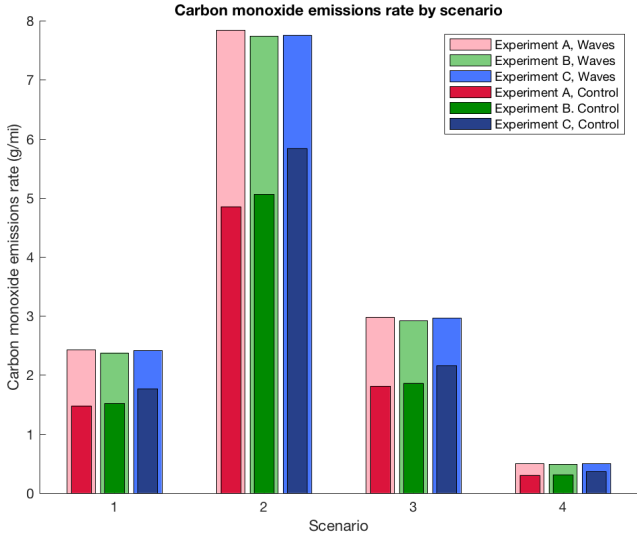

(b) Carbon monoxide emissions rate.

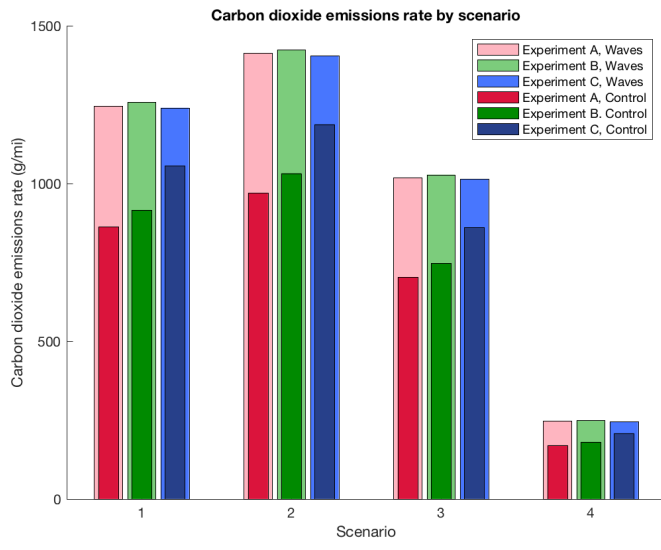

(d) Carbon dioxide emissions rate.

Figure 6: Emissions results for all four emissions categories for each experiment and fleet scenario considered showing both the emissions rate when waves are present and emissions rate when the traffic is under the control of the autonomous vehicle. 


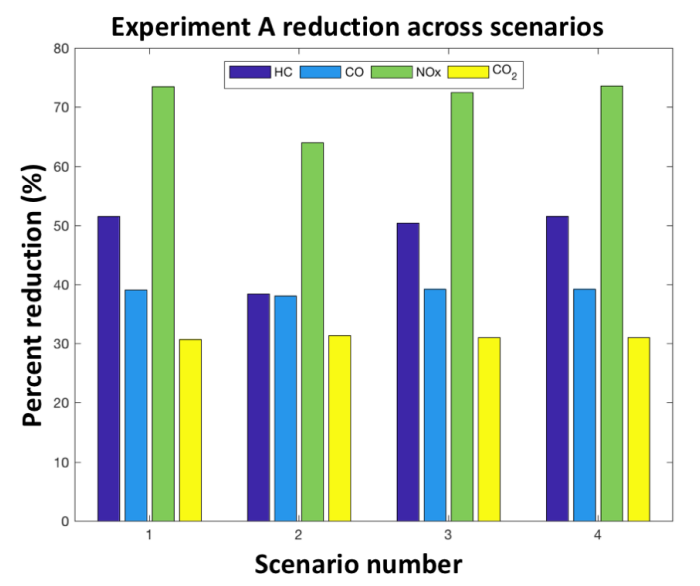

(a) Emissions reductions for all four fleet scenarios for Experiment A.

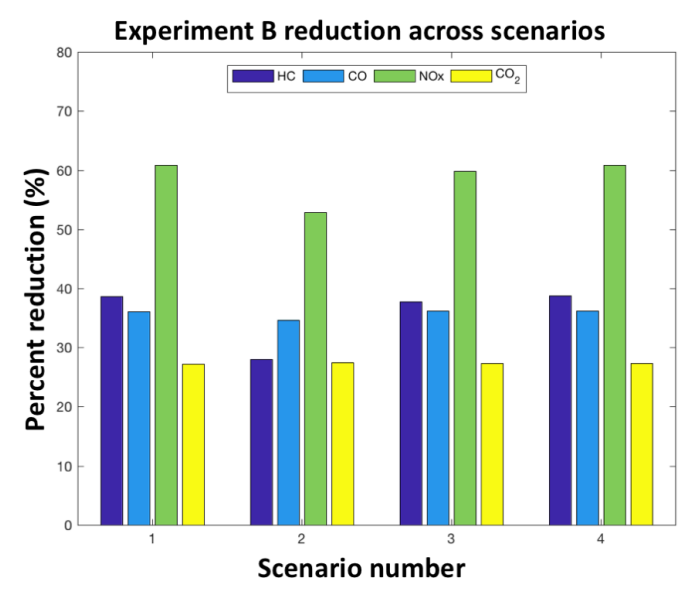

(b) Emissions reductions for all four fleet scenarios for Experiment B.

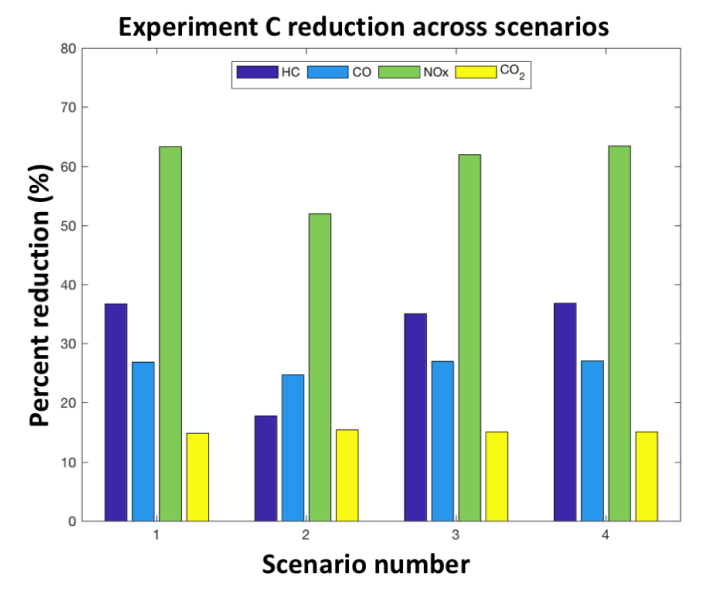

(c) Emissions reductions for all four fleet scenarios for Experiment C.

Figure 7: Emissions reduction for each experiment by scenario. Lighter shaded bar represents the average per-vehicle emissions rate in the presence of traffic waves for a specific experiment while the darker bar represents the reduced average per-vehicle emissions rate when the AV is actively dampening the traffic. Note the generally consistent reduction in emissions for each emissions category across the four fleet scenarios considered. 


\begin{tabular}{|c|c|c|c|c|c|c|c|c|c|c|c|c|}
\hline \multirow[b]{2}{*}{ Pollutant } & \multicolumn{3}{|c|}{ Scenario 1} & \multicolumn{3}{|c|}{ Scenario 2} & \multicolumn{3}{|c|}{ Scenario 3} & \multicolumn{3}{|c|}{ Scenario 4} \\
\hline & $\begin{array}{c}\mathrm{W} \\
(\mathrm{g} / \mathrm{mi})\end{array}$ & $\underset{(\mathrm{g} / \mathrm{mi})}{\mathrm{C}}$ & $\begin{array}{c}\mathrm{R} \\
(\%)\end{array}$ & $\begin{array}{c}\mathrm{W} \\
(\mathrm{g} / \mathrm{mi})\end{array}$ & $\underset{(\mathrm{g} / \mathrm{mi})}{\mathrm{C}}$ & $\begin{array}{c}\mathrm{R} \\
(\%)\end{array}$ & $\begin{array}{c}\mathrm{W} \\
(\mathrm{g} / \mathrm{mi})\end{array}$ & $\begin{array}{c}\mathrm{C} \\
(\mathrm{g} / \mathrm{mi})\end{array}$ & $\begin{array}{c}\mathrm{R} \\
(\%)\end{array}$ & $\begin{array}{c}\mathrm{W} \\
(\mathrm{g} / \mathrm{mi})\end{array}$ & $\underset{(\mathrm{g} / \mathrm{mi})}{\mathrm{C}}$ & $\begin{array}{c}\mathrm{R} \\
(\%)\end{array}$ \\
\hline $\mathrm{HC}$ & 0.010 & 0.005 & 51.5 & 0.191 & 0.125 & 38.4 & 0.019 & 0.010 & 50.4 & 0.003 & 0.002 & 51.6 \\
\hline $\mathrm{CO}$ & 2.430 & 1.481 & 39.1 & 7.843 & 4.854 & 38.1 & 2.984 & 1.812 & 39.3 & 0.503 & 0.305 & 39.3 \\
\hline $\mathrm{NO}_{\mathrm{x}}$ & 0.107 & 0.028 & 73.5 & 0.933 & 0.336 & 64.0 & 0.114 & 0.031 & 72.5 & 0.006 & 0.002 & 73.6 \\
\hline $\mathrm{CO}_{2}$ & 1246 & 863.1 & 30.7 & 1413 & 970.0 & 31.4 & 1019 & 703.0 & 31.0 & 246.7 & 179.2 & 31.0 \\
\hline
\end{tabular}

Table 4: Experimental results from Experiment A for period with waves (W) and best control period $(\mathrm{C})$ as identified in [37]. Reduction $(\mathrm{R})$ is computed as difference between period with waves and period when the AV is actively dampening traffic waves and smoothing the traffic flow. Note that the percent reduction is computed based on the projected emissions, while the emissions rates are only presented to at most three decimal places in this table.

\begin{tabular}{|c|c|c|c|c|c|c|c|c|c|c|c|c|}
\hline \multirow[b]{2}{*}{ Pollutant } & \multicolumn{3}{|c|}{ Scenario 1} & \multicolumn{3}{|c|}{ Scenario 2} & \multicolumn{3}{|c|}{ Scenario 3} & \multicolumn{3}{|c|}{ Scenario 4} \\
\hline & $\begin{array}{c}\mathrm{W} \\
(\mathrm{g} / \mathrm{mi})\end{array}$ & $\underset{(\mathrm{g} / \mathrm{mi})}{\mathrm{C}}$ & $\begin{array}{c}\mathrm{R} \\
(\%)\end{array}$ & $\begin{array}{c}\mathrm{W} \\
(\mathrm{g} / \mathrm{mi})\end{array}$ & $\underset{(\mathrm{g} / \mathrm{mi})}{\mathrm{C}}$ & $\begin{array}{c}\mathrm{R} \\
(\%)\end{array}$ & $\begin{array}{c}\mathrm{W} \\
(\mathrm{g} / \mathrm{mi})\end{array}$ & $\underset{(\mathrm{g} / \mathrm{mi})}{\mathrm{C}}$ & $\begin{array}{c}\mathrm{R} \\
(\%)\end{array}$ & $\begin{array}{c}\mathrm{W} \\
(\mathrm{g} / \mathrm{mi})\end{array}$ & $\underset{(\mathrm{g} / \mathrm{mi})}{\mathrm{C}}$ & $\begin{array}{c}\mathrm{R} \\
(\%)\end{array}$ \\
\hline $\mathrm{HC}$ & 0.010 & 0.006 & 38.7 & 0.189 & 0.136 & 28.0 & 0.018 & 0.011 & 37.8 & 0.003 & 0.002 & 38.7 \\
\hline $\mathrm{CO}$ & 2.380 & 1.520 & 36.1 & 7.740 & 5.060 & 34.6 & 2.920 & 1.860 & 36.1 & 0.491 & 0.314 & 36.2 \\
\hline $\mathrm{NO}_{\mathrm{x}}$ & 0.095 & 0.037 & 60.8 & 0.872 & 0.411 & 52.9 & 0.101 & 0.041 & 59.8 & 0.005 & 0.002 & 60.8 \\
\hline $\mathrm{CO}_{2}$ & 1260 & 916.0 & 27.2 & 1420 & 1030 & 27.5 & 1030 & 748.0 & 27.3 & 249.0 & 181.0 & 27.3 \\
\hline
\end{tabular}

Table 5: Experimental results from Experiment B for period with waves (W) and best control period $(\mathrm{C})$ as identified in [37]. Reduction (R) is computed as difference between period with waves and period when the AV is actively dampening traffic waves and smoothing the traffic flow. Note that the percent reduction is computed based on the projected emissions, while the emissions rates are only presented to at most three decimal places in this table.

\begin{tabular}{|c|c|c|c|c|c|c|c|c|c|c|c|c|}
\hline \multirow[b]{2}{*}{ Pollutant } & \multicolumn{3}{|c|}{ Scenario 1} & \multicolumn{3}{|c|}{ Scenario 2} & \multicolumn{3}{|c|}{ Scenario 3} & \multicolumn{3}{|c|}{ Scenario 4} \\
\hline & $\begin{array}{c}\mathrm{W} \\
(\mathrm{g} / \mathrm{mi})\end{array}$ & $\underset{(\mathrm{g} / \mathrm{mi})}{\mathrm{C}}$ & $\begin{array}{c}\mathrm{R} \\
(\%)\end{array}$ & $\begin{array}{c}\mathrm{W} \\
(\mathrm{g} / \mathrm{mi})\end{array}$ & $\underset{(\mathrm{g} / \mathrm{mi})}{\mathrm{C}}$ & $\begin{array}{c}\mathrm{R} \\
(\%)\end{array}$ & $\begin{array}{c}\mathrm{W} \\
(\mathrm{g} / \mathrm{mi})\end{array}$ & $\underset{(\mathrm{g} / \mathrm{mi})}{\mathrm{C}}$ & $\begin{array}{c}\mathrm{R} \\
(\%)\end{array}$ & $\underset{(\mathrm{g} / \mathrm{mi})}{\mathrm{W}}$ & $\underset{(\mathrm{g} / \mathrm{mi})}{\mathrm{C}}$ & $\begin{array}{l}\mathrm{R} \\
(\%)\end{array}$ \\
\hline $\mathrm{HC}$ & 0.010 & 0.006 & 36.8 & 0.191 & 0.157 & 17.8 & 0.019 & 0.012 & 35.1 & 0.003 & 0.002 & 36.8 \\
\hline $\mathrm{CO}$ & 2.420 & 1.770 & 26.9 & 7.760 & 5.840 & 24.7 & 2.960 & 2.160 & 27.1 & 0.500 & 0.364 & 27.1 \\
\hline $\mathrm{NO}_{\mathrm{x}}$ & 0.101 & 0.037 & 63.3 & 0.884 & 0.424 & 52.0 & 0.107 & 0.041 & 61.9 & 0.006 & 0.002 & 63.4 \\
\hline $\mathrm{CO}_{2}$ & 1240 & 1060 & 14.8 & 1410 & 1190 & 15.5 & 1010 & 861.0 & 15.1 & 245.0 & 208.0 & 15.1 \\
\hline
\end{tabular}

Table 6: Experimental results from Experiment $\mathrm{C}$ for period with waves (W) and best control period $(\mathrm{C})$ as identified in [37]. Reduction (R) is computed as difference between period with waves and period when the AV is actively dampening traffic waves and smoothing the traffic flow. Note that the percent reduction is computed based on the projected emissions, while the emissions rates are only presented to at most three decimal places in this table. 
Putting these numbers into perspective, the impact that vehicle electrification has on the overall vehicle (tailpipe) emissions is roughly proportional to the number of combustion engine vehicles being replaced with electric vehicles. This is because, from a modelling perspective, EVs do not impact source emissions, and MOVES does not include power plant emissions to produce the electricity elsewhere. By replacing combustion engine vehicles with human-piloted electric vehicles, source polluters are being replaced with vehicles that have no tailpipe emissions but still contribute to congestion. Note that this does not include a possible increase in vehicle miles traveled by electric vehicles because of the perceived reduced environmental impact or decrease in costs that consumers may feel when driving electric vehicles [17].

Thus, when looking at pollutants such as $\mathrm{NO}_{\mathrm{x}}$, replacing $5 \%$ of the vehicle fleet with properly-designed AVs has the same impact on emissions reduction as replacing roughly $75 \%$ of vehicles with electric vehicles. Importantly though, this only applies to driving conditions under which stop-and-go waves are present.

This work is limited in that it considers the emissions during stop-and-go traffic waves. These traffic waves are a common phenomenon in urban highway traffic but may only represent a small percentage of overall vehicle miles travelled by a typical driver. Therefore, it is unlikely that such significant reductions in emissions would be realized across an entire drive. However, there are additional benefits such as smoother driving and fewer braking events that are realized, even with partial vehicle fleet automation [37]. Additionally, the experiment was limited to a single AV and a limited track size. Therefore, only a small range of AV penetration rates could be experimentally tested. Regardless, the findings of this article indicate that significant reductions in vehicle emissions may be possible if only a small number of vehicles on the road are replaced with more technologically-advanced vehicles.

A limitation of the experimental setup used in this article is that there is only one lane of traffic, which is not typical for highway settings. However, importantly, the types of instabilities observed in this experimental setting are the same types of instabilities often observed on highways. Factors such as lane changing and merging, which are present on highways, may make it more difficult for an AV to dampen traffic waves. However, since the instabilities are the same types of instabilities observed in this experimental setting, the experimental results obtained in this experiment are applicable, though a higher AV penetration rate may ultimately be required to obtain the same reductions in emissions observed in this article.

Generally speaking, the FollowerStopper controller (Experiment A) is the most effective controller since it is able to reduce the vehicle emissions the most. This finding is consistent with the results reported by [37] where the FollowerStopper controller was able to achieve the greatest reduction in velocity standard deviation.

While the overall per-vehicle emissions are expected to decrease over the next several decades as vehicles are modernized and more stringent emissions standards are imposed, the impact that autonomous vehicles can have on reducing emissions remains relatively constant. This article finds that at a penetration rate of roughly 5\%, AVs will be able to reduce hydrocarbon emissions by as much as $51.6 \%$, carbon monoxide emissions by as much as $39.3 \%$, nitrogen oxide emissions by as much as $73.6 \%$, and carbon dioxide emissions by as much as $31.0 \%$ when comparing the smooth traffic under the control of AVs to the oscillatory traffic conditions observed with only human drivers. These AVs will enter our roadways in the near future regardless, so if properly designed to dampen traffic waves, this reduction in emissions comes at relatively little additional cost. Moreover, this reduction in emissions is not only realized by the AV, but manifested over the entire vehicle fleet, since all vehicles in the flow experience smoother driving behavior when the AV is actively dampening traffic waves. 


\section{Acknowledgements}

This material is based upon work supported by the National Science Foundation under Grants No. CNS1446715 (Piccoli), CNS-1446690 (Seibold), CNS-1446435 (Sprinkle), and CNS-1446702 (Work). This research was supported by the Inria associated team "ModEling autonoMous vEhicles iN Traffic flOw (MEMENTO)".

\section{References}

[1] K. Ahn, H. Rakha, A. Trani, and M. Van Aerde. Estimating vehicle fuel consumption and emissions based on instantaneous speed and acceleration levels. Journal of Transportation Engineering, 128(2):182-190, 2002.

[2] A. Alam, E. Diab, A. M. El-Geneidy, and M. Hatzopoulou. A simulation of transit bus emissions along an urban corridor: Evaluating changes under various service improvement strategies. Transportation Research Part D: Transport and Environment, 31:189-198, 2014.

[3] F. An, M. Barth, J. Norbeck, and M. Ross. Development of comprehensive modal emissions model: operating under hot-stabilized conditions. Transportation Research Record: Journal of the Transportation Research Board, 1587:52-62, 1997.

[4] M. André, M. Keller, Å. Sjödin, M. Gadrat, I. Mc Crae, and P. Dilara. The artemis european tools for estimating the transport pollutant emissions. In Proceedings of the 18th International Emission Inventories Conference, pages 1-10, 2009.

[5] K. J. Åström and R. M. Murray. Feedback Systems: An Introduction for Scientists and Engineers. Princeton University Press, 2008.

[6] M. Barth and K. Boriboonsomsin. Real-world carbon dioxide impacts of traffic congestion. Transportation Research Record: Journal of the Transportation Research Board, 2058:163-171, 2008.

[7] K. Boriboonsomsin, M. J. Barth, W. Zhu, and A. Vu. Eco-routing navigation system based on multisource historical and real-time traffic information. IEEE Transactions on Intelligent Transportation Systems, 13(4):1694-1704, 2012.

[8] A. Cappiello, I. Chabini, E. K. Nam, A. Lue, and M. A. Zeid. A statistical model of vehicle emissions and fuel consumption. In Proceedings of the 5th IEEE International Conference on Intelligent Transportation Systems (ITSC), pages 801-809. IEEE, 2002.

[9] L. Chapman. Transport and climate change: a review. Journal of Transport Geography, 15(5):354367, 2007.

[10] Y. Chen, J. Gonder, S. Young, and E. Wood. Quantifying autonomous vehicles national fuel consumption impacts: A data-rich approach. Transportation Research Part A: Policy and Practice, 2017.

[11] S. Cui, B. Seibold, R. Stern, and D. B. Work. Stabilizing traffic flow via a single autonomous vehicle: Possibilities and limitations. In 2017 IEEE Intelligent Vehicles Symposium (IV), pages 1336-1341, 2017. 
[12] P. De Haan, A. Peters, and R. W. Scholz. Reducing energy consumption in road transport through hybrid vehicles: investigation of rebound effects, and possible effects of tax rebates. Journal of Cleaner Production, 15(11):1076-1084, 2007.

[13] D. W. Dockery, C. A. Pope, X. Xu, J. D. Spengler, J. H. Ware, M. E. Fay, B. G. Ferris Jr, and F. E. Speizer. An association between air pollution and mortality in six us cities. New England Journal of Medicine, 329(24):1753-1759, 1993.

[14] Environmental Protection Agency. User's Guide to MOBILE6.1 and MOBILE6.2. Technical Report EPA-420-R-02-028, Environmental Protection Agency, 82003.

[15] Environmental protection Agency. Moves2014 and moves2014a technical guidance: Using moves to prepare emission inventories for state implementation plans and transportation conformity. Technical Report EPA-420-B-15-093, Environmental Protection Agency, 2015.

[16] D. J. Fagnant and K. Kockelman. Preparing a nation for autonomous vehicles: opportunities, barriers and policy recommendations. Transportation Research Part A: Policy and Practice, 77:167-181, 2015.

[17] D. Font Vivanco, J. Freire-González, R. Kemp, and E. van der Voet. The remarkable environmental rebound effect of electric cars: a microeconomic approach. Environmental science \& technology, 48(20):12063-12072, 2014.

[18] G. Fontaras, P. Pistikopoulos, and Z. Samaras. Experimental evaluation of hybrid vehicle fuel economy and pollutant emissions over real-world simulation driving cycles. Atmospheric Environment, 42(18):4023-4035, 2008.

[19] H. C. Frey, A. Unal, N. M. Rouphail, and J. D. Colyar. On-road measurement of vehicle tailpipe emissions using a portable instrument. Journal of the Air \& Waste Management Association, 53(8):9921002, 2003.

[20] M. Harb, Y. Xiao, G. Circella, P. L. Mokhtarian, and J. L. Walker. Projecting travelers into a world of self-driving vehicles: Estimating travel behavior implications via a naturalistic experiment. In Proceedings of the 97th Transportation Research Board Annual Meeting, Washington, DC, 2018.

[21] W. Harrington. Fuel economy and motor vehicle emissions. Journal of Environmental Economics and Management, 33(3):240-252, 1997.

[22] J. L. Jimenez, P. McClintock, G. J. McRae, D. D. Nelson, and M. S. Zahniser. Vehicle specific power: A useful parameter for remote sensing and emission studies. In Proceedings of the 9th CRC On-Road Vehicle Emissions Workshop, San Diego, CA, 1999.

[23] B. S. Kerner and P. Konhäuser. Cluster effect in initially homogeneous traffic flow. Physical Review E, 48(4):R2335, 1993.

[24] K. Kockelman, S. Boyles, P. Stone, D. Fagnant, R. Patel, M. W. Levin, G. Sharon, M. Simoni, M. Albert, H. Fritz, et al. An assessment of autonomous vehicles: Traffic impacts and infrastructure needs. Technical Report 0-6847-1, Texas Department of Transportation, 2017.

[25] C. Kouridis, L. Ntziachristos, and Z. Samaras. COPERT III: Computer Programme to Calculate Emissions from Road Transport: User Manual (version 2.1). European Environment Agency, 2000. 
[26] J. J. LaMondia, D. J. Fagnant, H. Qu, J. Barrett, and K. Kockelman. Shifts in long-distance travel mode due to automated vehicles: Statewide mode-shift simulation experiment and travel survey analysis. Transportation Research Record: Journal of the Transportation Research Board, 2566:1-11, 2016.

[27] J. Liu, K. Kockelman, and A. Nichols. Anticipating the emissions impacts of autonomous vehicles using the MOVES model. In Proceedings of the 95th Transportation Research Board Annual Meeting, Washington, DC, 2017.

[28] D. Mei, Y. Luo, W. Tan, P. Sun, and Y. Yuan. Comparative study of the transient emission profiles of a light-duty vehicle powered by petrodiesel and a light-duty vehicle powered by biodiesel (jatropha curcas). Proceedings of the Institution of Mechanical Engineers, Part D: Journal of Automobile Engineering, 230(1):93-102, 2016.

[29] H. Rakha, K. Ahn, and A. Trani. Comparison of mobile5a, mobile6, vt-micro, and cmem models for estimating hot-stabilized light-duty gasoline vehicle emissions. Canadian Journal of Civil Engineering, 30(6):1010-1021, 2003.

[30] H. Rakha, K. Ahn, and A. Trani. Development of VT-Micro model for estimating hot stabilized light duty vehicle and truck emissions. Transportation Research Part D: Transport and Environment, 9(1):49-74, 2004.

[31] R. D. Reitz and G. Duraisamy. Review of high efficiency and clean reactivity controlled compression ignition (rcci) combustion in internal combustion engines. Progress in Energy and Combustion Science, 46:12-71, 2015.

[32] F. Schäfer and R. Van Basshuysen. Reduced emissions and fuel consumption in automobile engines. Springer Science \& Business Media, 2013.

[33] D. Schuetzle. Sampling of vehicle emissions for chemical analysis and biological testing. Environmental Health Perspectives, 47:65, 1983.

[34] O. Servin, K. Boriboonsomsin, and M. Barth. An energy and emissions impact evaluation of intelligent speed adaptation. In Proceedings of the IEEE Intelligent Transportation Systems Conference (ITSC), pages 1257-1262. IEEE, 2006.

[35] S. A. Shaheen and T. E. Lipman. Reducing greenhouse emissions and fuel consumption: sustainable approaches for surface transportation. IATSS Research, 31(1):6-20, 2007.

[36] T. S. Stephens, J. Gonder, Y. Chen, Z. Lin, C. Liu, and D. Gohlke. Estimated bounds and important factors for fuel use and consumer costs of connected and automated vehicles. Technical Report NREL/TP-5400-67216, National Renewable Energy Laboratory (NREL), Golden, CO, 2016.

[37] R. E. Stern, S. Cui, M. L. Delle Monache, R. Bhadani, M. Bunting, M. Churchill, N. Hamilton, R. Haulcy, H. Pohlmann, F. Wu, B. Piccoli, B. Seibold, J. Sprinkle, and D. B. Work. Dissipation of stop-and-go waves via control of autonomous vehicles: Field experiments. Transportation Research Part C: Emerging Technologies, 89:205 - 221, 2018.

[38] Y. Sugiyama, M. Fukui, M. Kikuchi, K. Hasebe, A. Nakayama, K. Nishinari, S.-i. Tadaki, and S. Yukawa. Traffic jams without bottlenecks-experimental evidence for the physical mechanism of the formation of a jam. New Journal of Physics, 10(3):033001, 2008. 
[39] S.-i. Tadaki, M. Kikuchi, M. Fukui, A. Nakayama, K. Nishinari, A. Shibata, Y. Sugiyama, T. Yosida, and S. Yukawa. Phase transition in traffic jam experiment on a circuit. New Journal of Physics, 15(10):103034, 2013.

[40] H. Teng, L. Yu, and Y. Qi. Statistical microscale emission models incorporating acceleration and deceleration. In Proceedings of the 81st Transportation Research Board Annual Meeting, volume 29, 2002.

[41] H. Y. Tong, W. T. Hung, and C. S. Cheung. On-road motor vehicle emissions and fuel consumption in urban driving conditions. Journal of the Air \& Waste Management Association, 50(4):543-554, 2000.

[42] US Energy Information Administration. Annual Energy Outlook. https://www.eia.gov/ outlooks/aeo/data/browser/\#, 2017. Accessed: 2017-12-21.

[43] J. D. Vreeswijk, M. K. M. Mahmod, and B. Van Arem. Energy efficient traffic management and control-the ecomove approach and expected benefits. In Proceedings of the 13th IEEE International Conference on Intelligent Transportation Systems (ITSC), pages 955-961. IEEE, 2010.

[44] A. Wang, M. Fallah-Shorshani, J. Xu, and M. Hatzopoulou. Characterizing near-road air pollution using local-scale emission and dispersion models and validation against in-situ measurements. Atmospheric Environment, 142:452-464, 2016.

[45] F. Wu, R. Stern, S. Cui, M. L. Delle Monache, R. Bhadani, M. Bunting, M. Churchill, N. Hamilton, R. Haulcy, H. Pohlmann, B. Piccoli, B. Seibold, J. Sprinkle, and D. B. Work. Tracking vehicle trajectories and fuel rates in oscillatory traffic. Transportation Research Part C: Emerging Technologies, to appear, 2018.

[46] X. Xu, H. Liu, J. M. Anderson, Y. Xu, M. P. Hunter, M. O. Rodgers, and R. L. Guensler. Estimating project-level vehicle emissions with vissim and moves-matrix. Transportation Research Record: Journal of the Transportation Research Board, 2570:107-117, 2016.

[47] H. Yang and W.-L. Jin. A control theoretic formulation of green driving strategies based on intervehicle communications. Transportation Research Part C: Emerging Technologies, 41:48-60, 2014.

[48] H. Yang, H. Rakha, and M. V. Ala. Eco-cooperative adaptive cruise control at signalized intersections considering queue effects. IEEE Transactions on Intelligent Transportation Systems, 18(6):15751585, 2017.

[49] T. Zachariadis, L. Ntziachristos, and Z. Samaras. The effect of age and technological change on motor vehicle emissions. Transportation Research Part D: Transport and Environment, 6(3):221-227, 2001.

[50] Y. Zhao and A.l W. Sadek. Computationally-efficient approaches to integrating the moves emissions model with traffic simulators. Procedia Computer Science, 19:882-887, 2013. 